\title{
Abnormal sexual behaviors in male AY-bearing mice
}

JAMES D. HAWKINS

UNIVERSITY OF TEXAS
Two experimental outcomes are presented. In both of them yellow Mus musculus (genotype $A^{y_{a}}$ ) show a disability in adjusting to a changed environmental situation. In one case, using former breeders, yellow males sought to copulate with non-yellow male partners. The reverse was not found. In the other case, yellow males of one genotype attacked estrous females while the non-yellow males mated normally. An explanation is advanced involving the single gene substitution, the genetic background, and the pretesting experience of the animals.

Pioneer studies in behavior genetics have demonstrated that male inbred mice differ, by strain, on a number of copulatory measures (McGill \& Blight, 1963; Levine, Barsel, \& Diakow, 1966). $\mathrm{A}^{\mathrm{y}}$, the yellow lethal allele from the agouti locus on linkage group $V$. is maintained by forced heterozygosis on the C57BL/6J background by the Jackson Laboratory (Green, 1966). Wide differences on two activity measures have been found between $A^{Y_{a}}$ (yellow) and aa (black) animals from this stock (Hawkins, 1965, 1966). In that context it was noted that many of the outcomes from the earlier sex behavior studies could be interpreted in terms of differential activity between strains. It was also suggested that single gene substitutions might disrupt otherwise well buffered sexual and agonistlc behavior patterns. This report gives two cases where Ay was found to produce abnormal mating responses in $\mathrm{C57BL} / 6 \mathrm{~J}$ males. Both outcomes can be related to the subject's pretesting experience but not to genetically determined activity differences.

\section{Experiment 1}

This work was primarily concerned with changes in fighting behavior patterns attributable to $A Y$. Ten black and 10 yellow males (146-212 days old) were retired from breeding service and housed as isolates for 30-38 days. They were then paired for $15 \mathrm{~min}$ tests in a clrcular arena $18 \mathrm{in}$. in diameter and $16 \mathrm{in.}$ high (see Hawkins, 1966, for detailed description). Tallies were kept for nuzzling, attacking, retreating, tall-rattling, and mount attempts between pairs. The Wilcoxon matched-pairs, slgned-ranks test (Slegel, 1956) indicated that there were significant differences ( $p<.01$ ) on all measures except for tall-rattling. The $A^{y_{a}}$ animals showed social dominance on all of the significant measures. There was no overlap between genotypes for retreats or mount attempts. Seven of the $10 \quad A^{y_{a}}$ Ss made repeated and persistent mount attempts in their pairings, whereas none of the aa Ss did.

\section{Experiment 2}

This experiment directly tested genotypic effects on a number of female as well as male sex behaviors. The following genotypes were used: $C 57 \mathrm{BL} / 6 \mathrm{~J}$ (aa), C57BL/6J - $\mathrm{A}_{\mathrm{a}}^{\mathrm{y}}, \mathrm{DBA} / 2 \mathrm{~J}$ (as), $\mathrm{B6D2F}_{1}$ (aa), and $\mathrm{B} 6 \mathrm{D} 2 \mathrm{~F}_{1}-\mathrm{AJa}$. Ten males from each genotype were tested every other day for a total of five observations each. Every male was tested with one female from each of the five genotypes. The females were in induced estrus (see McGill \& Blight, 1963).

Quantitative differences were found between genotypes on several mating pattern components in both males and females. These will be reported in a separate paper. Male outoomes in this experiment, where comparable to those of McGill \& Blight (1963), yjelded very similar results despite procedural differences. This paper emphasizes an unexpected result. One qualitatively different behavior pattern was found to be genotype dependent in males. All of the C57BL/ $6 \mathrm{~J}-\mathrm{AY}_{\mathrm{a}}$ and one of the $\mathrm{C57BL} / 6 \mathrm{~J}$ (aa) males made attacks on one or more of the females they were paired with. These males exhibited the plloerection, balled-posture, and stiff-legged locomotion of fighter mice. Their attacks usually drew blood. None of the animals from the other three genotypes showed this behavior. Only two, of the 11 affected Ss, attacked on all five trials (the an genotype was one of these). Three of them copulated. One of these attacked the first three females he was paired with, did not attack the fourth, and achieved ejaculation with the fifth. Discussien

Bartke \& Wolff (1966) have been concerned with the effects of $A^{Y}$ on mating effectiveness in the YS/Ch Wf strain. McGill has had a continuing series of sex behavior studies with the stocks used here but not with $A^{y}$. Personal communication from these workers is that they have not observed such attacking behavior. The writer, also, has not seen it except in this experiment. C57BL/6J-A $\mathrm{Y}_{\mathrm{a}}$ animals of both sexes reproduce readily under normal colony conditions.

A rational explanation is that a genotype by experimental manipulation interaction is involved. Three factors seem to contribute to the aberrant patterns: the $A^{y}$ substitution, the genotypic background, and the pretesting environment. In Experiment 1, isolation was employed in an effort to provoke between-male fighting. The animals did fight, but in the context of repeated and vigorous mount attempts by the $A_{y_{2}}$ males. These males had previously been used as 
breeders. In Experiment 2, the males were housed in groups of five, with one member of each genotype present, from weaning through the first 10 weeks of life. Thereafter (for about six weeks, including time in the experiment), they were housed as isolates because fighting and wounding were observed in the group cages.

In each case the animals had been isolated and, when paired with another mouse, the affected animals acted as might be expected in their pre-isolation environment. In both testing situations, much genital nuzzling was seen. In the affected $\mathrm{Ss}$ this either did not lead to a sex discrimination, or else a stereotyped habit had to be overcome, before more appropriate behavior occurred. The latter alternative seems more likely since several $\mathrm{A}_{\mathbf{a}} \mathrm{y}_{\mathrm{males}}$ eventually copulated and one reached ejaculation in Experiment 2. Apparently attacking females, in this situation, is strain as well as gene dependent, since $\mathrm{B} 6 \mathrm{D} 2 \mathrm{~F}_{1}-\mathrm{A} \mathrm{Y}_{\mathrm{a}}$ males did not show the behavior while one C57BL/6J (aa) male did.

\section{References}

BARTKE, A., \& WOLFF, G. L. Influence of the lethal yellow ( $A$ y) gene on estrous synchrony in mice. Science, 1966, 153, 79-80.

GREEN, E. L. (Ed.) Biology of the laboratory mouse. (2nd ed.). New York: McGraw-Hill, 1966.

HAWKINS, J. D. Effects of the $\mathrm{A}^{\mathrm{y}}$ substitution on mouse activity level: Spurious pleiotropy. Psychon. Sci, 1965, 3, 269-270.

HAWKINS, J. D. Developmental effects of the $A^{y}$ substitution on mouse activity level. Psychon. Sci., 1966, 4, 105-106.

LEVINE, L., BARSEL, GAIL E., \& DIAKOW, CAROL A. Mating behavior of two inbred strains of mice. Anim. Behav., 1966, 14, 1-6.

McGILL, T. E., \& BLIGHT, W. C. The sexual behavior of hybrid male mice compared with the sexual behavior of males of the inbred parent strains. Anim. Behav., 1963, 11, 480-483.

SIEGEL, S. Nonparametric statistics. New York: McGraw-Hill, 1956.

\section{Note}

1. This work was done at Claremont Graduate School and was supported by predoctoral fellowship MH 16, 374 from the National Institute of Mental Health. Part of the data are from the author's Ph.D. dissertation. The report preparation was supported by postdoctoral fellowship HD 16, 374 G \& D. National Institute of Child Health and Human Development. 